\title{
The Contribution of Meta-Cognitive Guidance to Building Geometry Teaching Units and Improving Classroom Teaching Processes
}

\author{
Erez Nahmias $^{1} \&$ Mina Teicher ${ }^{1}$ \\ ${ }^{1}$ Bar-Ilan University, Ramt-Gan, Israel \\ Correspondence: Erez Nahmias, Bar-Ilan University, Ramt-Gan, Israel. E-mail: 555NSIH@gmail.com
}

Received: August 30, 2020 Accepted: December 15, 2020 Online Published: December 30, 2020

doi:10.5539/jel.v10n1p55 URL: https://doi.org/10.5539/jel.v10n1p55

\begin{abstract}
In this paper, we examine the importance of building instructional units that incorporate metacognition intent processes that contribute to the development of geometric thinking. We show that the implementation of metacognition processes in the initial stages of constructing tailored instructional units will improve students' geometric ability. The study was performed on middle school mathematics teachers of the ninth grade. The experiment we conducted shows that building instructional units that incorporate metacognition intent benefit learning processes on two levels: First, in the subject matter. Second, they contribute to a deeper understanding that improves student's ability to connect related subjects to mathematical geometry. moreover, we will present a practical model that incorporates different aspects that could operate a guideline for middle school mathematics teachers.
\end{abstract}

Keywords: self-directed learning, metacognition, geometric thinking

\section{Introduction and Related Work}

Multiple studies have shown the relationship between metacognition and academic achievement (Perry, Lundie, \& Golder, 2019). Specifically, that learning outcomes improve as more metacognitive processes occur during learning (Beyer, 2001). Although metacognitive thinking develops with age and experience, its development can be accelerated and elevated through instruction that is directed toward it. Metacognitive instruction enhances metacognitive thinking itself and students' achievement in various disciplines. This kind of teaching has been shown to be particularly effective for low-achieving students (Zohar \& Ben David, 2008). Scholars, mathematicians, and educators have pointed out that learning strategies have a major role in the development of abstract thinking (Houdement \& Kuzniak, 2003). One of the main questions that has been studied is what is the optimal way to develop thinking processes in a student. Until the 1980s, research was mainly focused on abstract thinking and cognition. In the 1980s, metacognition was introduced This approach claims that for a learning process to be exhausted and meaningful, the following four components must take place: First, cognition is all the internal processes of information processing that mediate between the stimulus and the response i.e., cognition refers to all the knowledge and information available to the person and to the processes in which they were acquired, processed and implemented (Flavell, 1979). These internal processes are: thinking, perception, understanding, learning, attention, memory, drawing conclusions, making decisions and solving problems. Second, motivation characterizes the learner who continues the learning process even when there is no external supervision and no rewards or sanctions. Third, metacognition is high-level thinking, the individual's knowledge and awareness of his or her own cognitive processes and the ability to actively direct and monitor them (Kramarski, 2000). With the help of cognitive and meta-cognitive skills, achievements can be improved (Schraw, 1998). Fourth, context learning is a high self-directed learning, where the student regulates his behavior according to context, environment and learning situations.

A learning process that contains all four components (cognition, motivation, metacognition, context learning) is called self-directed learning. Each one of the four components has been studied separately and in context of the whole self-directed learning model. One such branch is called self-regulated learning (SRL) which refers to creating thoughts, emotions and will in the learning process to achieve the wanted learning goals. This subject has been studied from multiple aspects (Pintrich, 2000; Zimmerman, 1990). They show that self-directed students have the ability to develop goal-oriented learning based on adapting approaches to learning specific topics. This type of studying is characterized by the ability of the student to control cognition, motivation, 
metacognition and context learning.

Self-guidance in learning containing all four of its components presented above has been proven in Pisa (2012) to be effective for developing mathematical literacy. Mathematical literacy has been defined as a person's ability to formulate, apply, and interpret mathematics in a variety of contexts and identify the role that mathematics plays in the world.

By reviewing the statistical outcome from the Pisa exams (Pisa, 2012), we see that there is a correlation between students with high-performance in the exam and students with the ability to autodidact themselves by reading the needed material (Pintrich, 2000). They propose that the challenge of self-directed learning is to teach students, with appropriate intervention and support, to simultaneously regulate the various aspects of learning: planning, implementing strategies, managing the learning time, motivation, collaborative learning, etc. These processes enable the student to take an active part in learning (Michalsky, 2012).

Studies dealing with the relationship between metacognition and educational achievement consistently show that educational outcomes improve as more meta-cognitive processes occur during learning. Although meta-cognitive thinking develops with age and experience, it is possible to accelerate its development through teaching aimed at doing so. Metacognitive teaching improves meta-cognitive thinking itself and student achievement in various topics (Kramarski, 2000).

This method of teaching is particularly effective for low-achieving students (Zohar \& Ben David, 2008). Through this instruction, they are instructed on how to build the whole from its parts.

From all of the above, one can discern the importance and contribution of self-direct learning. As can be seen, self-direct learning incorporates metacognition - one of the most important cornerstones in the development of thinking. To establish precise metacognitive guidance, it must already be integrated into the construction of the teachers' study units. In our study, we will present the model we built based on the degree of status quo before using the model and the results after using the model.

\section{The Research Approach}

\subsection{Metacognition Intent Teaching Model}

In order to examine how we can improve and develop the geometric thinking processes among middle-school students, we examined the difficulties that currently exist in the teaching model. In discourse with teachers and examination of the geometry study units that exist today, they were found to be aimed at knowledge transfers only. The need that arises is to give the student tools for self-guidance in learning and thereby to contribute to the development of geometric thinking. It is shown that the main barrier is the gap between the abstract geometric level required from students in the elementary schools versus the level required in the middle school. Therefore, in this paper, we focus on the differences in the development of teaching units that combine metacognitive guidance with those that do not. Moreover, we are interested to check if metacognitive guided lessons produce better geometrical understanding for students.

Table 1. The question model allows the teacher to incorporate within the lesson plans, the processes, and skills required of the student

\begin{tabular}{ll}
\hline Criteria & The questions a teacher should ask himself \\
\hline Target & What is the purpose of a lesson? what is the main idea of the lesson? The topic of the lesson, mathematical \\
& knowledge, required explanations and examples. How can I achieve the lesson objectives? \\
Context & $\begin{array}{l}\text { What examples do I need to present in class? Why? If this is not the first lesson, what is the similarity and } \\
\text { difference between the examples I have already provided? What is the purpose of the difference? }\end{array}$ \\
Strategy & $\begin{array}{l}\text { What are the practices and strategies to be used in teaching this lesson? Why? What is a good geometric } \\
\text { discourse? }\end{array}$ \\
Self-Examination & $\begin{array}{l}\text { What difficulties have emerged while teaching this lesson? Have the lesson objectives been achieved? Were } \\
\text { students involved in the lesson? Could I plan the assignment/lesson differently? }\end{array}$ \\
\hline
\end{tabular}

The Question Model directs the teacher to focus on four criteria that help one to assimilate and correct the subject being studied. The four model criteria give the teacher the opportunity to pinpoint their goals and help students develop geometric thinking and learning skills.

\subsection{Research Question}

The premise on which we approached the research question was that metacognitive guidance could help build 
teaching units. Also, the guideline was that building teaching units through guidance processes would contribute to improving teaching processes. The research question as presented below will deal with the relationship between building teaching units and improving learning processes. As presented above, the processes of more metacognitive guidance have an emphasis on learning processes among students and less on teaching processes among teachers. Quality teaching processes are the basis for meaningful learning processes. The student will be able to improve his abilities only when the teachers' teaching strategies allow learning that weaves knowledge and thinking throughout the process.

The model built and presented above helped us to pinpoint the research questions. Our goal was to examine how metacognition guidance helps teachers during the construction of study units. Another question we wanted to examine was how lesson plans that had been built with metacognition guidance contributed to improving teaching in the classroom. The hypothesis that we assumed was that developing study units that combined the questions of metacognition guidance would help to develop students thinking and modeling.

\subsection{Research Design}

To assess the proposed model, a questionnaire was designed for eight middle-school teachers who were participants assumed to be teaching geometry to nine-graders, specifically, the subject geometry of the plane. Each participant was requested to develop eight teaching units, where each teaching unit was designed for a 45 minutes frontal lesson and to follow the proposed model.

Teachers asked to choose a topic in the geometry of the plane. The request was that the new subject is based on prior knowledge in geometric. Teachers chose different topics in geometry. This figure is important since metacognitive intent is significant not only for a particular subject but as a guideline in building teaching units that improve teaching processes.

The study units were constructed based on the guiding questions that the same teachers received as shown in Table 1. The goal was to integrate metacognitive learning while learning. The group of teachers is diverse in their years of experience in teaching, but we would like to show that the construction of teaching units in metacognitive guidance processes is required for every teacher.

The assignment and the following questionnaire were given to 14 middle school Israeli teachers to complete. The distribution of the teachers' experience was assumed to be normally distributed and the mean and std was calculated to be 21.214 and 11.369 in years, respectively. As a result, we argue that the results well represent teachers with a wide range of experience. $71.43 \%$ of the participants were female and the other $28.57 \%$ male. Also, $71.43 \%$ of the participants have a Bachelors's degree while $28.57 \%$ have a Masters's degree.

The reliability of the questionnaire is 0.804 in the Alpha Cronbach index. The questionnaire has constructed to examine the extent of the contribution of metacognitive guidance from the perspective of teachers who studied geometry in classrooms.

Afterwards, each participant was asked to complete a questionnaire (as presented in Table 2). Each participant was asked before completing the questionnaire, by a member of one the research team, to scrutinize the way they develop teaching units with and without the proposed model.

Table 2. The questionnaire answered by the research participants (ranging from 1 to 5 according to the Likert scale)

\begin{tabular}{ll}
\hline Question Symbol & Question \\
\hline Q1 & $\begin{array}{l}\text { Has the construction of a teaching unit combined with the intentional processes encouraged understanding in } \\
\text { the studied subjects? } \\
\text { Q2 }\end{array}$ \\
& $\begin{array}{l}\text { Has the construction of the teaching unit combined with the intentional processes encouraged the } \\
\text { development of geometric thinking among the students? }\end{array}$ \\
Q3 & Did the innovation (referred to in the previous section) contribute to development of a better teaching unit? \\
Q4 & Did the guidance questions improve your way of teaching? \\
\hline
\end{tabular}

\subsection{Data Analysis \& Results}

In total, 112 teaching units were developed and the questionnaire were answered by the same participants. The results of the questionnaire are shown in Figure 1. The x-axis is the answer's value; the y-axis is the percent of participants who chose this option. Each color represents answers for a different question in the questionnaire. 
The average score of all the answers (ranging from 1 to 5 according to the Likert scale) to the questionnaire is 4.043 with standard deviation of 0.624 (0.804 in the Alpha Cronbach index). The data in Figure 1 clearly show that developing a teaching unit that incorporates meta-cognitive guidance has a major contribution to developing students' thinking processes according to the teacher's self-observation. This is because any score higher than 3 indicates an improvement. The average score is almost 1.5 standard deviations above 3 showing statistically meaningful results. One can conclude that developing a teaching unit that integrates the intentional processes allows the teacher to examine the learning process both before its implementation and afterwards. The teacher has the opportunity to reflect on the learning process and thereby improve over time. The teacher evolves the geometric language among the students in the learning processes and enriches the thinking strategies that contribute to students learning more topics using metacognitive intentional processes and tools.

The results of the present study clearly show the importance of building teaching units with the help of metacognitive intent. Researchers (Perry, Lundie, \& Golder, 2019) have noted the importance of assimilating metacognitive guidance in teaching. The present study more specifically discusses the importance of building metacognitive-oriented teaching units in geometric. A geometry study in high schools is a complex subject that is a barrier for many students. The construction of teaching units is a perceptual change in the way teaching methods and the ability to integrate higher-order thinking in geometry.

The teachers' answers indicate the positive relationship between teaching units has constructed with the help of metacognitive guidance in geometry and improvement in learning processes. The model allows teachers to ask themselves questions. Asking the questions helps in process accuracy and particular in processes that require more thinking and less built-in algorithm (Weinbaum, Allen, Blythe, Simon, Seidel, \& Rubin, 2004).

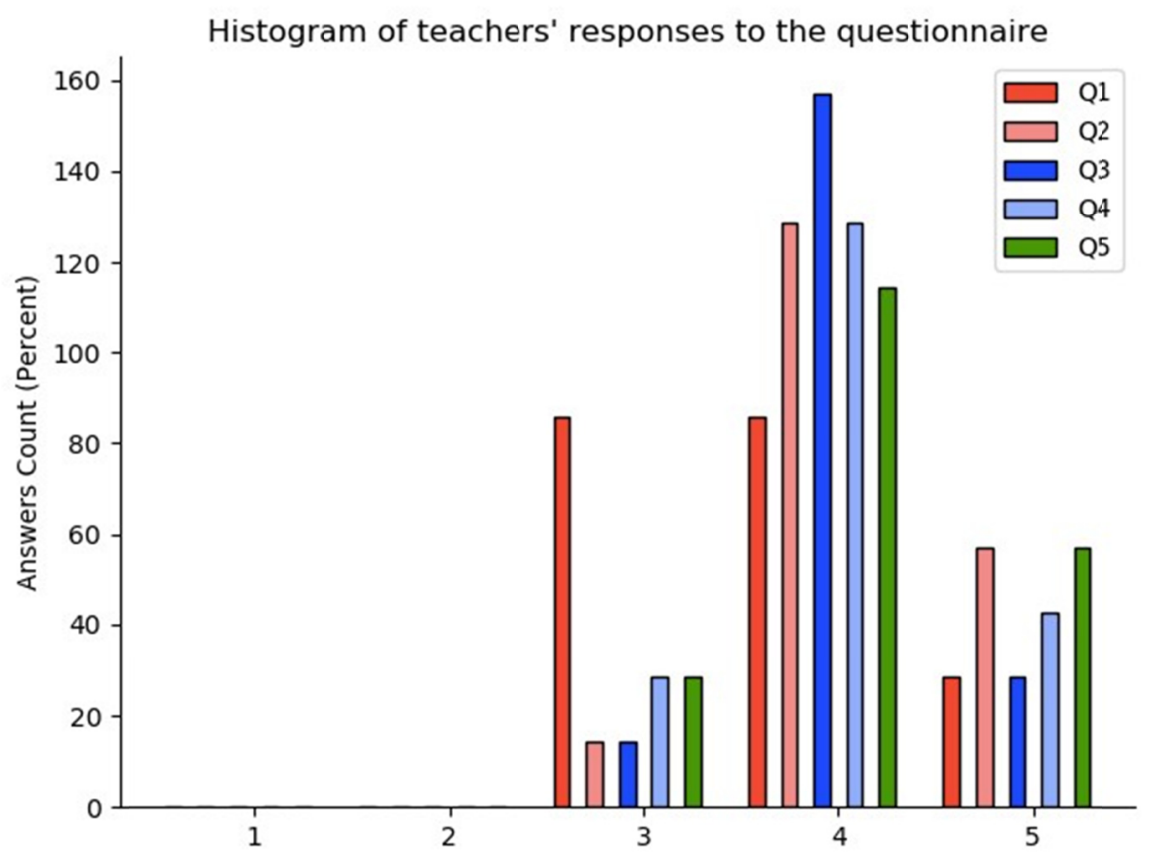

Figure 1. Histogram of middle-school teachers' answers to the questionnaire

\section{Discussion}

The primary role of teachers is to improve the quality of thinking of learners and to teach them how to use it consciously, effectively and structurally (Beyer et al., 2001). In self-directed learning, the component of metacognitive intention is very significant as it provides a foundation for learning that integrates and supports high-order thinking. Geometry studies for middle school students require conceptualization, abstraction, and logical proof writing.

Students in their first year of middle school in Israel start from the point where they do not know how to write a mathematical proof, and therefore the idea of conceptualization is new to them. At this point in their studies to 
perform well in the mathematical level excepted from them, the students need to write proofs that are based on a set of mathematical theorems which they need to understand, remember and be able to implement. The data from the experiment show that the proposed pedagogical unit-developing method improves the students' abstract thinking. A majority of $64.28 \%$ of the participants answered that they feel that the guidance questions helped them build a geometric teaching unit, while $28.57 \%$ feel it was slightly helpful.

Teaching units that combine metacognitive guidance were constructed so that the questions were aimed at establishing four criteria: purpose, context, strategies, and assessment. These distinctions as presented in the model are sharpened by the questions. Participants' responses indicate that $28.6 \%$ of them did not emphasize the "model" of teaching strategies. It was also found that the participants reported lack of purpose (14.3\%), context (14.3\%), and assessment (14.3\%). In addition, the participants reported the lack of more than one distinguishing factor in the construction of instructional units before the "model" was implemented. Context and Evaluation (14.3\%), Context and Strategies (14.3\%).

It is easy to see that the current teaching and learning processes are given minority emphasis on developing thinking abilities and learning skills. With the use of the "model" we can see that there has been a change in the trend and the learning process has encouraged the development of thinking in general and geometric thinking in particular. Most participants noted that strategies for incorporating instructional units had not been incorporated before using the proposed model.

Most of the participants (78.57\%) declared that the proposed model contributed to the construction of a better teaching unit. The contribution of the "model" was not only reflected in the development of geometric thinking but in addition, $85.71 \%$ of the participants declared that developing a teaching unit and with the combination of metacognitive guidance processes, encouraged understanding and integration between the studied topics.

In addition, $85.71 \%$ of the participants declared that the proposed model encouraged the development of geometric thinking among students. By combining all the results presented so far, one can notice that the development of geometric thinking is a product of systematic and orderly metacognitive guidance.

\section{Conclusion}

The ability to give the teacher a pedagogical model such that one can establish learning that interweaves the four criteria: purpose, context, strategies and assessment is significant and constitutes an important anchor in the advancement of geometry studies.

The pedagogical model that we built allows teachers to examine the study units as to whether they are indeed promoting and improving learning. Direction questions improve the study units but also improve the quality of teaching as teachers have pointed out. The improvement is evident in its attribution to context, strategies, and evaluation. Improvement in each parameter will help to develop clearly geometric language and also encourage significant development of geometric thinking.

We propose the following four suggestions to be promising research topics and policy change recommendations to strengthen the current results: First, providing tools and skills to students in mathematics teaching in building teaching units that incorporate metacognitive guidance. Second, professional development for teachers teaching mathematics on the importance and significance to develop geometric thinking. Third, encouraging research to develop abstract geometric thinking not only on the plane but in other spaces. Fourth curricula in geometry must be written that incorporate meta-cognitive guidance processes.

\section{References}

Beyer, B. K. (2001). What Research Says About Teaching Thinking Skills. In A. L. Costa (Ed.), Developing Minds: A Resource Book for Teaching Thinking (pp. 275-282).

Dignath, C., \& Büttner, G. (2008). Components of fostering self-regulated learning among students. A meta-analysis on intervention studies at primary and secondary school level. Metacognition Learning, 3, 231-264. https://doi.org/10.1007/s11409-008-9029-x

Flavell, J. H. (1979). Metacognition and cognitive monitoring: A new area of cognitive-developmental inquiry. American Psychologist, 906-911. https://doi.org/10.1037/0003-066X.34.10.906

Houdement, C., \& Kuzniak, A. (2013). Elementry geometry split into different geometrical paradigms. European Research in Mathematcis Education. Didirem Université Denis Diderot, Paris. France.

Kramarski, B. (2000). Metacognition and the ability to solve math problems presented in concrete and abstract context. Megamot, 660-685. 
Michalsky, T. (2012). Integrating skills and wills instruction in self-regulated science text reading for secondary student. International Journal of Science Education, 35(11), 1846-1873. https://doi.org/10.1080/09500693.2013.805890

Perry, J., Lundie, D., \& Golder, G. (2019). Metacognition in schools: What does the literature suggest about the effectiveness of teaching metacognition in schools? Educational Review, 71(4), 483-500. https://doi.org/10.1080/00131911.2018.1441127

Pintrich, P. R. (2000). The role of goal orientation in self-regulated learning. The University of Michigan, Ann Arbor. In Handbook of Self-Regulation (pp. 451-529). https://doi.org/10.1016/B978-012109890-2/50043-3

PISA, Programme for International Student Assessment. (2012). Retrieved from https://cms.education.gov.il/educationcms/units/rama/mivchanimbenleumiyim/pisa+2012.htm

Schraw, G. (1998). Promoting general metacognitive awareness. Instructional Science (An International Journal of the Learning Science), 26, 113-125. https://doi.org/10.1023/A:1003044231033

Weinbaum, A., Allen, D., Blythe, T., Simon, K., Seidel, S., \& Rubin, C. (2004). Teaching as Inquiry: Asking Hard Questions to Improve Practice and Student achievement. Oxford, Ohio. National staff development Council.

Zimmerman, B. J. (1990). Self-Regulated learning and academic achievement: An overview. Educational Psychology, 25, 3-17. https://doi.org/10.1207/s15326985ep2501_2

Zohar, A., \& David, A. B. (2008). Explicit teaching of meta-strategic knowledge in authentic classroom situations. Metacognition Learning, 3, 59-82. https://doi.org/10.1007/s11409-007-9019-4

\section{Copyrights}

Copyright for this article is retained by the author, with first publication rights granted to the journal.

This is an open-access article distributed under the terms and conditions of the Creative Commons Attribution license (http://creativecommons.org/licenses/by/4.0/). 